\title{
Unusual Clinical Presentation of Autosomal Recessive Woolly Hair
}

\author{
Osama Alsharif Azhar Abbas Ahmed Azhar Mohammed Alali \\ Adnan Ahmed Kaki \\ Department of Dermatology, Ministry of Health, King Fahad General Hospital, Madinah, Saudi Arabia
}

\section{Established Facts}

- Autosomal recessive woolly hair/hypotrichosis $(\mathrm{ARWH} / \mathrm{H})$ is a nonsyndromic hair abnormality characterized by sparse, short, and curly hair.

- The patient's hair is usually blond or lighter than other family members. ARWH is due to mutation in the P2RY5 or lipase H (LIPH) gene or LPAR6.

\section{Novel Insights}

- The case presented does not describe the typical classic morphology of woolly hair that is part of the $\mathrm{ARWH} / \mathrm{H}$, probably because of the very fine thin hair which may obscure the woolly nature of the individual hair, emphasizing the importance of genetic hair testing to reach the accurate precise diagnosis and proper genetic counselling.

\section{Keywords}

Hair disorder · Hair dysplasia · Autosomal recessive hypotrichosis

\section{Abstract}

Autosomal recessive woolly hair/hypotrichosis $(\mathrm{ARWH} / \mathrm{H})$ is a rare nonsyndromic hair abnormality characterized by sparse, short, and curly hair. we report a case of a 5-year-old girl from consanguineous parents, who presented with ARWH/H since birth. Dermoscopic findings showed thin sparse hair. Genetic testing showed homozygous mutation in the LPAR6 gene.

(c) 2020 S. Karger AG, Basel

\section{Introduction}

Childhood alopecia is a relatively rare disorder in general pediatric dermatology practice. Alopecia in children may have multiple causes; acquired or genetic possibilities represent broadly different types of alopecia according to age groups [1].

Cortés et al. [2] mentioned that the most common etiology of childhood alopecia was acquired nonscarring alopecia. But this study does not deny the existence of genetic causes of alopecia such as the case presented herein.

Autosomal recessive woolly hair/hypotrichosis (ARWH/H) (OMIM \#278150/604379) is a rare nonsyndromic genetic hair disorder manifesting as tightly

\section{KARGER}

(C) 2020 S. Karger AG, Basel

karger@karger.com

www.karger.com/sad
Osama Alsharif

Ministry of Health, King Fahad General Hospita

King Abdullah Branch Road, Sayed As Shuhada

Medinah 42321 (Saudi Arabia)

E-Mail osama1426@yahoo.com 


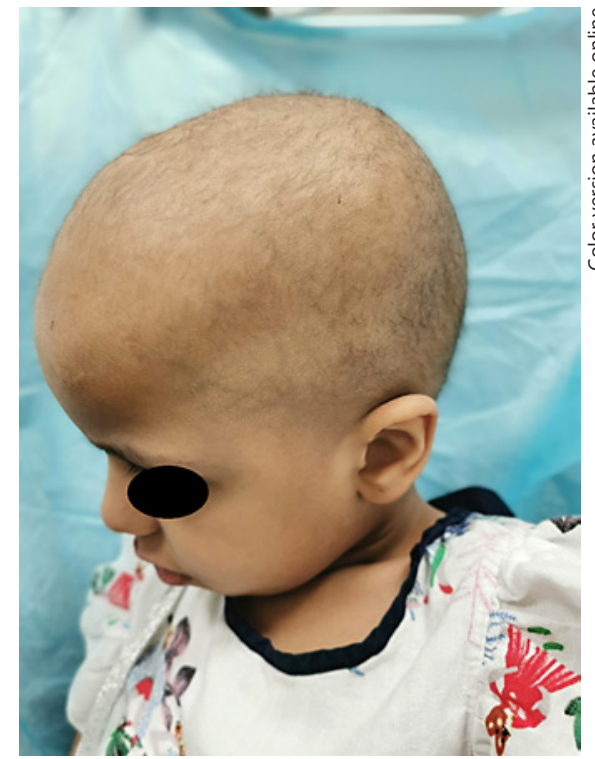

Fig. 1. Fine sparse hair over the patient's scalp: lateral view.

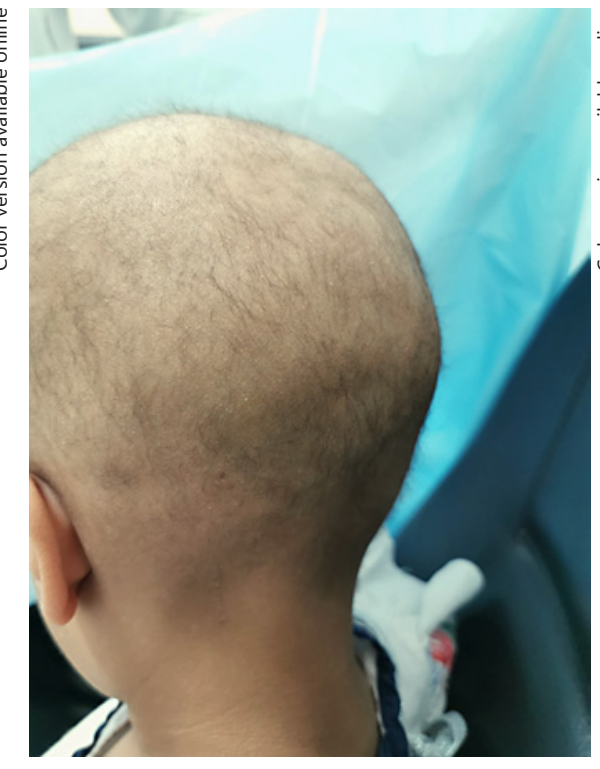

Fig. 2. Fine sparse hair over the patient's scalp: occipital view.

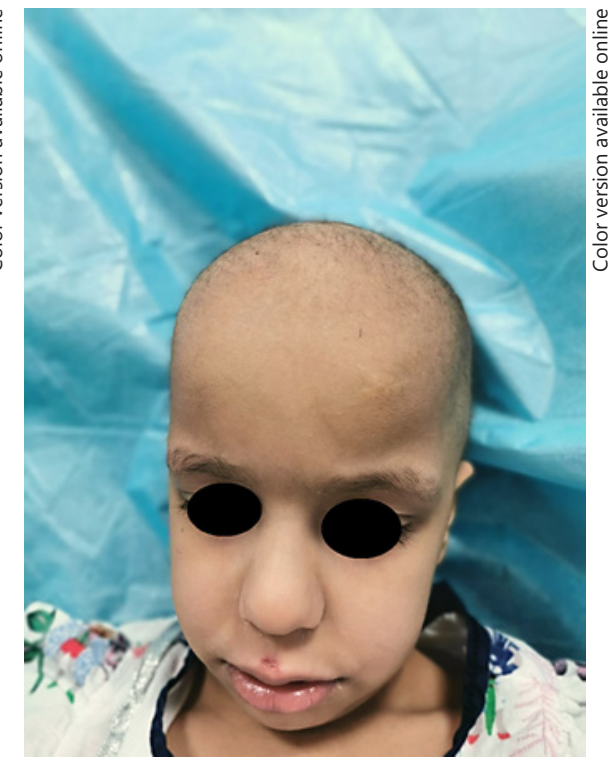

Fig. 3. The patient's eyebrows and eyelashes appear normal.

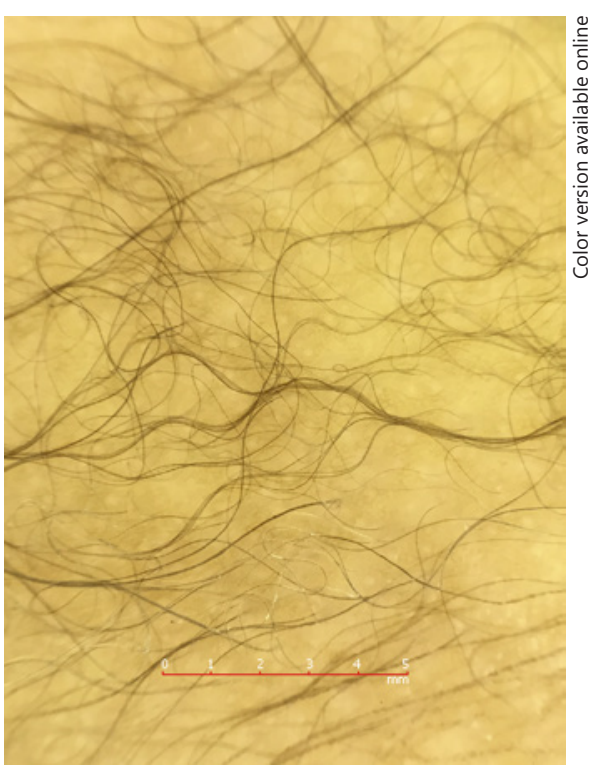

Fig. 4. Trichoscopic image of scalp hair.

curled sparse scalp hair sometimes expanding to all body hair [3]. The patient's hair is usually blond or lighter than other family members [4]. ARWH is due to mutation in the P2RY5 or lipase $\mathrm{H}(L I P H)$ gene or LPAR6. Zernov et al. [5] and Takeichi et al. [6] document that KRT25 may also cause ARWH.

Autosomal Recessive Woolly Hair

\section{Case Report}

A 5-year-old Saudi girl presented to our dermatology clinic with the complaint of short sparse hair since birth. She never had her hair cut. Her eyelashes, eyebrows, nails, teeth, and sweating appeared normal. Her delivery had been normal and her development otherwise unremarkable. There was no family history of similar hair condition on her father's or mother's side.

Physical examination showed fine sparse hair ranging in length from 1 to $3 \mathrm{~cm}$ (Fig. 1,2). her eyebrows and eyelashes were unaffected (Fig. 3) and laboratory tests were all normal. Dermoscopy showed thin hair shafts with tapered ends (Fig. 4).

Whole exome sequencing was done and the LPAR6 gene was detected in a homozygous state. The consequence of this variant is a premature stop codon, triggering nonsense-mediated decay which leads to loss of protein (c.373_374delAA).

\section{Discussion}

Interestingly, the patient presented with sparse fine hair without the curly nature of the disease, diverting from the classic phenotypic manifestation of ARW/H. $\mathrm{ARWH} / \mathrm{H}$ is due to mutation in the P2RY5 or $L I P H$ gene or LPAR6. Zernov et al. [5] and Takeichi et al. [6] document that KRT25 may also cause ARWH.

$L I P H$ encodes PA-PLA $A_{1} \alpha$, a phospholipase $A_{1}$ family member that produces lysophosphatidic acid (LPA) from phosphatidic acid and plays an important role in human hair growth [7]. Moreover, P2RY5 is another gene (which 
is expressed in both Henle's and Huxley's layers of the inner root sheath of the hair follicle) that encodes a $G$ protein-coupled receptor P2Y5 that binds to LPA. Both PA$\mathrm{PLA}_{1} \alpha$ and $P 2 R Y 5$ are expressed in the inner root sheath of the hair follicle [8].

Al Aboud et al. [9] reported a family in Saudi Arabia with ARWH/H where 2 girls suffered from sparse curly scalp hair a few years after birth, both with axilla involvement but normally appearing other body hair. The girls' father was the only member of the family who had curly hair. The 2 girls were diagnosed as ARWH/H based on the clinical findings and the family history.

Shimomura et al. [10] in 2008 reported several Pakistani families with ARWH/H. the scalp hair was coarse, lusterless, and tightly curled. The plucked hairs showed dystrophic features without root sheath components in the bulb region. Eyebrows, eyelashes, and beard hairs were normal. There were no ectodermal defects.

The clinical course of ARWH/H varies. The hair abnormalities may be evident at birth or may develop several months after birth, or the hair volume may increase with age [11]. This fluctuation in the clinical course of the disease suggests that $L I P H$ is associated with unidentified, linked genes, which may be up- or downregulated or may be modified by single nucleotide polymorphisms, resulting in inner sheath development with age [11].

\section{Conclusion}

The case presented does not describe the typical classic morphology of woolly hair that is part of the ARWH/H probably because of the very fine thin hair which may ob- scure the woolly nature of the individual hair, emphasizing the importance of genetic hair testing to reach the accurate precise diagnosis and proper genetic counselling.

\section{Acknowledgments}

We gratefully acknowledge the family members involved in this study.

\section{Disclosure Statement}

The authors have no conflicts of interest to declare.

\section{Statement of Ethics}

All procedures followed were in accordance with the ethical standards of the responsible committee on human experimentation (institutional and national) and with the Helsinki Declaration of 1964, as revised in 2013. The patient's parents gave their written informed consent to publish the case and images.

\section{Funding Sources}

No funding or sponsorship was received for this article.

\section{Author Contributions}

All named authors meet the international committee of Medical Journal Editors (ICMJE) criteria for authorship of this article, take responsibility for the integrity of the work as a whole, and gave their approval for this version to be published.

\section{References}

1 Ahmed A, Almohanna H, Griggs J, Tosti A. Genetic hair disorders: a review. Dermatol Ther (Heidelb). 2019 Sep;9(3):421-48.

2 Cortés GA, Mardones VF, Zemelman DV. [Aetiology of childhood alopecia]. Rev Chil Pediatr. 2015 Jul-Aug;86(4):264-9. Spanish.

3 Horev L, Tosti A, Rosen I, Hershko K, Vincenzi C, Nanova K, et al. Mutations in lipase $\mathrm{H}$ cause autosomal recessive hypotrichosis simplex with woolly hair. J Am Acad Dermatol. 2009 Nov; 61(5):813-8. German.

4 Salamon T. [On a family with the recessive trait of woolly hair, hypotrichosis and other anomalies]. Hautarzt. 1963 Dec;14:540-4.

5 Zernov NV, Skoblov MY, Marakhonov AV, Shimomura Y, Vasilyeva TA, Konovalov FA, et al. Autosomal recessive hypotrichosis with woolly hair caused by a mutation in the keratin 25 gene expressed in hair follicles. J Invest Dermatol. 2016 Jun;136(6):1097-105.

6 Takeichi T, Tanahashi K, Taki T, Kono M, Sugiura K, Akiyama M. Mutational analysis of 29 patients with autosomal-recessive woolly hair and hypotrichosis: LIPH mutations are extremely predominant in autosomal-recessive woolly hair and hypotrichosis in Japan. Br J Dermatol. 2017 Jul;177(1):290-2.

7 Itoh E, Nakahara T, Furumura M, Furue M, Shimomura Y. Case of autosomal recessive woolly hair/hypotrichosis with atopic dermatitis. J Dermatol. 2017 Oct;44(10):1185-6.

8 Shimomura Y, Wajid M, Zlotogorski A, Lee YJ, Rice RH, Christiano AM. Founder mutations in the lipase $\mathrm{H}$ gene in families with autosomal re- cessive woolly hair/hypotrichosis. J Invest Dermatol. 2009 Aug;129(8):1927-34.

$9 \mathrm{Al}$ Aboud K, Al Aboud D. Autosomal recessive hypotrichosis simplex with woolly hair: a report of a new family. Dermatol Rep. 2011 Aug; 3(2):e13.

10 Shimomura Y, Wajid M, Ishii Y, Shapiro L, Petukhova L, Gordon D, et al. Disruption of P2RY5, an orphan G protein-coupled receptor, underlies autosomal recessive woolly hair. Nat Genet. 2008 Mar;40(3):335-9.

11 Matsuno N, Kunisada M, Kanki H, Simomura Y, Nishigori C. A case of autosomal recessive woolly hair/hypotrichosis with alternation in severity: deterioration and improvement with age. Case Rep Dermatol. 2013 Dec;5(3):363- 